\title{
On $\Delta$ Generalised Star Semi-Closed Sets in Topological Spaces
}

\section{S. Rajakumar}

Abstract: A modern form of sets labeled $\delta g *^{*}$-closed sets is imported in this material. A part of utilization of $\delta g{ }^{*} s$-closed sets and its resources are explained. A modernistic space called $\delta g *_{s-} *_{3 / 4}-$ space is also popularized.

Keywords: $\delta$-closed sets, $\delta$-open sets, $\delta g{ }^{*}$ s-open sets, $\delta g{ }^{*}$ s-closed sets and $\delta g{ }^{*} \mathrm{~s}-\mathrm{T}{ }_{3 / 4}-$ space.

\section{INTRODUCTION}

In 1968, Velicko [13] introduced the $\delta$ closed sets. Some authors([1], [4], [8], [10], [11]) continuing their studies on semi-closed sets and continuous maps on topological spaces. $\mathrm{g}^{*} \mathrm{~s}$-closed sets were made known by the topologist [14]. $\delta \mathrm{g}^{*} \mathrm{~s}$-closed sets and $\delta \mathrm{g}^{*} \mathrm{~s}-\mathrm{T}^{*}{ }_{3 / 4}-$ space are popularized in this note by the author.

\section{PRELIMINARIES}

In every place of this text $(\mathrm{N}, \tau)$ or $\mathrm{N}$ perform topological spaces. Definitions of g, sg, gs, $\alpha \mathrm{g}, \delta \mathrm{g}, \alpha \mathrm{g}$-closed sets are collected from [5], [2], [7], [6], [3], [12], [9], [14].

\section{MAIN RESULTS}

Definition 3.1 A division $M$ of $(N, \tau)$ is termed as , $\delta \mathrm{g}^{*} \mathrm{~s}$ closed if $\operatorname{cl}_{\delta}(\mathrm{M}) \subseteq \mathrm{V}$ whenever $\mathrm{M} \subseteq \mathrm{V}, \mathrm{V}$ is $\mathrm{g}^{*} \mathrm{~s}$ - open.

Theorem 3.2 Each one $\delta$-closed $\Rightarrow \delta g *$ s -closed set.

Proof. Approve $U \subseteq \delta$-closed, $\mathrm{V} \subseteq \mathrm{g}{ }^{*} \mathrm{~s}$-open consisting of $\mathrm{U}$. As $\operatorname{cl}_{\delta}(\mathrm{U})=\mathrm{U}$ for each $\subset \mathrm{U}$ of $\mathrm{N}$. Thus $\operatorname{cl}_{\delta}(\mathrm{U}) \subseteq \mathrm{U} \Rightarrow \mathrm{U}$ is $\delta g^{*}$ s-closed.

Note 3.3, $\delta \mathrm{g}^{*} \mathrm{~s}$-closed $\Rightarrow \delta$-closed.

Revised Manuscript Received on December 15, 2019.

* Correspondence Author

S. Rajakumar*, Assistant Professor, Department of Mathematics, Kalasalingam Academy of Research And Education, Krishnankoil-626 126, India, Email: srkumar277@gmail.com
Example 3.4 Let $N=\{m, n, o, p\}$ with the topology $\tau=\{N$, $\varphi,\{m\},\{n\},\{m, n\},\{m, n, o\}\}$. Though the set $\{o$, $\mathrm{p}\}$ is $\delta \mathrm{g}^{*} \mathrm{~s}$--closed it is not $\delta$-closed.

Proposition $3.5 \delta \mathrm{g}^{*} \mathrm{~s}$ closed $\Rightarrow$ g-closed set.

Proof. Authorize $U=\delta g^{*} \mathrm{~s}$-closed, $\mathrm{V}=$ open set consists of U.

Here $\mathrm{U}$ is $\delta \mathrm{g}^{*} \mathrm{~s}$ closed, $\mathrm{cl}_{\delta}(\mathrm{U}) \subseteq \mathrm{U}$ for each $\mathrm{U}$ of $\mathrm{N}$. As cl(U) $\subseteq \mathrm{cl}_{\delta}(\mathrm{U}) \subseteq \mathrm{U}, \operatorname{cl}(\mathrm{U}) \subseteq \mathrm{U}$, consequently $\mathrm{U}$ is g-closed.

Example 3.6 Let $\mathrm{N}=\{\mathrm{s}, \mathrm{t}, \mathrm{u}, \mathrm{v}\}, \tau=\{\mathrm{N}, \quad \varphi, \quad\{\mathrm{s}\}$, $\{t\},\{s, \quad t\},\{t, u, v\}\}$. Then $\{v\}$ is g-closed set and $\neq \delta g^{*} s$ -closed in N. This example proves that g-closed $\neq \delta g^{*} \mathrm{~s}$ -closed.

Theorem 3.7 Every $\delta \mathrm{g}^{*} \mathrm{~s}$-closed $\Rightarrow$ gs-closed.

Proof. Presume $U=\delta g * s-$ closed. $V=$ open set consists of U. As cl $(\mathrm{U}) \subseteq \mathrm{U}$ for every $\subset \mathrm{U}$ of $\mathrm{N}$. As $\operatorname{scl}(\mathrm{U}) \subseteq$ $\mathrm{cl}_{\delta}(\mathrm{U}) \subseteq \mathrm{V}, \operatorname{scl}(\mathrm{U}) \subseteq \mathrm{V}, \Rightarrow \mathrm{U}$ is gs-closed.

Example 3.8 Let $\mathrm{N}=\{\alpha, \kappa, \quad \theta, \psi\}, \tau=\{\mathrm{N}, \quad \varphi, \quad\{\alpha\}$, $\{\kappa\},\{\alpha, \kappa\},\{\kappa, \theta, \quad \psi\}\}$. Though $\{\theta\}$ is gs-closed $\neq$ $\delta \mathrm{g}^{*} \mathrm{~s}-$ closed. This shows that gs-closed $\neq \delta \mathrm{g}^{*} \mathrm{~s}-$ closed.

Theorem 3.9 $\delta \mathrm{g}^{*} \mathrm{~s}$-closed $\Rightarrow$ ag-closed set.

Proof. For each $U$ of $N$, It is clear that $\alpha \operatorname{cl}(\mathrm{U}) \subseteq \mathrm{cl}_{\delta}(\mathrm{U})$.

Example 3.10 Let $N=\{1,2,3,4\}, \quad \tau=\{N, \varphi$, $\{1\},\{2\},\{1,2\},\{2,3,4\}\}$. Then $\{1,3\}$ is ag-closed set $\delta g^{*} \mathrm{~s}$-closed. However converse part fails in Theorem 3.9.

Theorem 3.11 $\delta \mathrm{g}^{*} \mathrm{~s}$-closed $\Rightarrow \delta \mathrm{g}$-closed set.

Proof. Suppose $\mathrm{U} \subseteq \delta \mathrm{g}^{*} \mathrm{~s}$-closed, $\mathrm{V}$ the open set consists of $\mathrm{U}$. $\mathrm{As}_{\delta}(\mathrm{A}) \subseteq \mathrm{U}$, when $\mathrm{A} \subseteq \mathrm{U}, \mathrm{U}$ is $\mathrm{g}^{*} \mathrm{~s}$-open. There upon $\mathrm{cl}_{\delta}(\mathrm{U}) \subseteq \mathrm{U}, \mathrm{U}$ is open. Thus $\mathrm{U}$ is $\delta$ g-closed.

Example 3.12 Take $\mathrm{N}=\{\chi, \psi, \gamma, \delta\}, \quad \tau=\{\mathrm{N}$, $\varphi, \quad\{\chi\}, \quad\{\psi\}, \quad\{\chi, \psi\},\{\psi, \gamma, \delta\}\}$. Then $\{\chi, \delta\}$ is $\delta$ g- closed set $\neq \delta g^{*}$ s -closed in N . It proves that confer gets blunder in Theorem 3.11. 


\section{On $\Delta$ Generalised Star Semi-Closed Sets in Topological Spaces}

Theorem 3.13 $\delta g^{*}$ s -closed $\Rightarrow \alpha g^{\wedge}$-closed set.

Proof. For every D of (L, $\tau), \alpha \operatorname{cl}(\mathrm{D}) \subseteq \mathrm{cl}_{\delta}(\mathrm{D})$ is clear.

Example 3.14 Let $N=\{\eta, \kappa, \lambda, \mu\}$, with the topology $\tau=\{N, \varphi,\{\eta\},\{\kappa\},\{\eta, \kappa\},\{\kappa, \lambda, \mu\}\}$. Then $\{\eta, \kappa, \lambda\}$ is $\alpha \mathrm{g}^{\wedge}$-closed set $\neq \delta \mathrm{g}^{*} \mathrm{~s}$--closed in $\mathrm{N}$. Hence exchange is not perfect in Theorem 3.13.

Note 3.15 Examples for relationships of $\delta g^{*} \mathrm{~s}$-closed with more noted sets.

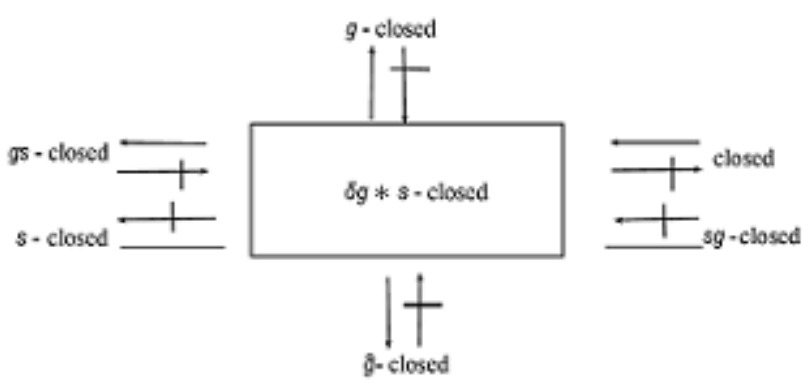

Remark 3.16 Self-reliant results with $\delta g^{*}$ s -closed are given below.

Illustration 3.17 Assume $N=\{\eta, \sigma, \rho\}, \tau=\{\mathrm{N}, \varphi,\{$

$\eta\}\{\sigma\},\{\eta, \sigma\}\}$. Then $\{\eta, \sigma\}$ is $\delta \mathrm{g}^{*} \mathrm{~s}-$ closed but $\neq \mathrm{g}^{*} \mathrm{~s}$ -closed and $\neq$ sg-closed

Example 3.18 Take $\mathrm{N}=\{\gamma, \rho, \sigma, \mathrm{s}\}$ with the topology $\tau=$ $\{\mathrm{N}, \varphi,\{\gamma\},\{\gamma, \rho\},\{\sigma, \mathrm{s}\},\{\gamma, \sigma, \mathrm{s}\}\}$. Then $\{\gamma, \rho\}$ is $\delta \mathrm{g} * \mathrm{~s}$ closed but $\neq \mathrm{g} \alpha$ $\neq \alpha$-closed.

Illustration 3.19 Assume $\mathrm{N}=\{\theta, \sigma, \omega, \psi\}$ with the topology $\tau=\{N, \varphi,\{\theta\},\{\sigma\},\{\theta, \sigma\},\{\sigma, \omega, \psi\}\}$. Then $\{\theta, \omega\}$ is $\mathrm{g}^{*} \mathrm{~s}, \mathrm{sg}, \mathrm{g} \alpha$-closed and $\neq \delta \mathrm{g} * \mathrm{~s}$-closed.

Illustration 3.20 Consider $\mathrm{N}=\{\gamma, \eta, \pi$,$\} with the$ topology $\tau=\{N, \varphi, \quad\{\gamma\},\{\gamma, \eta\},\{\pi, \rho\},\{\gamma, \pi, \rho\}\}$. Then $\{\gamma\}$ is $\alpha$-closed and $\neq \delta \mathrm{g}^{*}$-closed set.

\section{IV.CHARACTERIZATIONS}

Theorem 4.1 The limited combination of $\delta g^{*} \mathrm{~s}-$ closed sets $\rightarrow$ $\delta \mathrm{g} * \mathrm{~s}$ closed.

Proof. Endorse $\left\{X_{i} / \mathrm{i}=1,2, \ldots . \mathrm{n}\right\}$ be a limited set of $\delta \mathrm{g}^{*} \mathrm{~s}$-closed subsets N. Moreover for $\mathrm{N}_{i}, \operatorname{cl}_{\delta}\left(\mathrm{X}_{i}\right) \subseteq \mathrm{U}_{i}, \mathrm{i} \in$ $\{1,2, \ldots \mathrm{n}\}$. Hence $\mathrm{N}_{i} \subseteq \bigcup \mathrm{U}_{i}=\mathrm{V}$. Here $\mathrm{U}$ of $\mathrm{g}^{*}$ s-open $=$ $\mathrm{g}{ }^{*} \mathrm{~s}$-open in $\mathrm{N}$. V is $\mathrm{g}{ }^{*} \mathrm{~s}$-open in $\mathrm{N}$. In addition, $U \mathrm{cl}_{\delta}\left(\mathrm{N}_{i}\right)=$ $\mathrm{cl}_{\delta}\left(\bigcup \mathrm{N}_{i}\right) \subseteq \mathrm{V}$. Therefore $\bigcup \mathrm{N}_{i}$ is $\delta \mathrm{g}^{*} \mathrm{~s}$-closed in $\mathrm{N}$.
Observation 4.2 $\cap$ of $\delta \mathrm{g}^{*} \mathrm{~s}$-closed sets in $\mathrm{L} \neq \delta \mathrm{g} * \mathrm{~s}$-closed set. In example $3.14\{\eta, \kappa, \lambda,\} \cap\{\eta, \kappa, \mu\}=\{\eta, \kappa\}$ is $\neq \delta g^{*} \mathrm{~s}$ -closed.

Theorem 4.3 If $E$ is a $\delta g^{*} \mathrm{~s}-$ closed $\subset$ of $\mathrm{N}$, then $\mathrm{cl}_{\delta}(\mathrm{E})-\mathrm{E}$ not $\subseteq$ an $\mathrm{g}^{*} \mathrm{~s}$-closed set.

Proof. Take $\mathrm{U}$ as $\delta \mathrm{g}^{*} \mathrm{~s}$-closed and assume $\mathrm{G}$ be a $\mathrm{g}{ }^{*} \mathrm{~s}$ closed set contained in $\operatorname{cl}_{\delta}(\mathrm{U})-\mathrm{U}$. Now $\mathrm{G}^{c}=\mathrm{g}^{*} \mathrm{~s}$ open set of $\mathrm{N}$, likewise $\mathrm{U} \subset \mathrm{G}^{c}$. As $\mathrm{U}=\delta \mathrm{g}^{*} \mathrm{~s}$-closed set of $\mathrm{N}$, then $\operatorname{cl}_{\delta}(\mathrm{U})$ $\subseteq \mathrm{G}^{c}$. Thus $\mathrm{G} \subseteq\left(\mathrm{cl}_{\delta}(\mathrm{U})\right)^{\mathrm{c}}$. Also $\mathrm{G} \subseteq \mathrm{cl}_{\delta}(\mathrm{U})-\mathrm{U}$. Therefore $\mathrm{G}$ $\subseteq\left(\mathrm{cl}_{\delta}(\mathrm{U})\right)^{\mathrm{c}} \cap\left(\mathrm{cl}_{\delta}(\mathrm{U})\right)=\phi$. Thus $\mathrm{G}=\phi$.

Theorem 4.4 In N, $U=g * s$ open, $\delta g^{*} \mathrm{~s}-$ closed $\subset$ of $\mathrm{N}$ then is $\delta$-closed $\subset$ of $\mathrm{N}$.

Proof. As $\mathrm{g}^{*} \mathrm{~s}$-open and $\delta \mathrm{g} * \mathrm{~s}-\operatorname{closed}=\mathrm{U}, \mathrm{cl}_{\delta}(\mathrm{U}) \subseteq \mathrm{U}$. Hence $\mathrm{U}$ is $\delta$-closed.

Theorem 4.5 In $\mathrm{T}_{3 / 4}$-space each one $\delta \mathrm{g}^{*} \mathrm{~s}$-closed set $\Rightarrow$ $\delta$-closed.

Proof. Consider $\mathrm{U}$ be $\delta \mathrm{g}^{*} \mathrm{~s}$-closed set of $\mathrm{N}$, where $\mathrm{N}$ is $\mathrm{T}_{3 / 4}$-Space. Here, each one $\delta \mathrm{g} * \mathrm{~s}$-closed set $\rightarrow \delta \mathrm{g}$ closed. Therefore $\mathrm{N}$ is $\mathrm{T}_{3 / 4}$-Space and $\mathrm{U}$ is $\delta$-closed.

Theorem 4.6 In N, U is $\delta$-closed and $\delta \mathrm{g}^{*} \mathrm{~s}$-closed if and only if $\mathrm{cl}_{\delta}(\mathrm{U})-\mathrm{U}=\mathrm{g} * \mathrm{~s}$-closed.

Proof. Necessity. Assume $U$ be a $\delta$-closed $\subset$ of N. Then $\mathrm{cl}_{\delta}(\mathrm{U})=\mathrm{U}$ and so $\mathrm{cl}_{\delta}(\mathrm{U})-\mathrm{U}=\varphi$, a g*s -closed.

Adequate: As $U$ is $\delta g^{*} \mathrm{~s}-$ closed by Theorem $4.3, \operatorname{cl}_{\delta}(\mathrm{A})-\mathrm{A} \neq$ $\mathrm{g}^{*}$ s-closed. $\operatorname{But~}_{\delta}(\mathrm{U})-\mathrm{U}=\varphi$. That is $\operatorname{cl}_{\delta}(\mathrm{U})=\mathrm{U}$. Hence $\mathrm{U}$ is $\delta$-closed.

\section{APPLICATIONS}

Definition 5.1 $\mathrm{N}$ is termed as $\delta \mathrm{g}^{*} \mathrm{~S}-\mathrm{T}^{*}{ }_{3 / 4}$-space if each $\delta \mathrm{g}^{*}$ s-closed set $\Rightarrow \delta$-closed.

Theorem 5.2 Every $\mathrm{T}_{3 / 4}$-space is a $\delta \mathrm{g}^{*} \mathrm{~s}-\mathrm{T}_{3} * / 4-$ space.

Proof. Here each $\delta \mathrm{g}^{*} \mathrm{~s}$-closed $\Rightarrow \delta$-closed, the argument is clear.

Remark $5.3 \delta \mathrm{g}^{*} \mathrm{~s}-\mathrm{T}^{*}{ }_{3 / 4}$-space $\neq \mathrm{T}^{*}{ }_{3 / 4}$-space.

Illustration 5.4Consider $\mathrm{N}=\{\delta, \pi, \theta\}$ and $\tau=\{\mathrm{N}, \varphi$, $\{\delta\}\}$. $\mathrm{N}$ is a $\delta \mathrm{g}^{*} \mathrm{~s}-\mathrm{T}^{*}{ }_{3 / 4}$-space but not a $\mathrm{T}^{*}{ }_{3 / 4^{-}}$space.

Published By:

Blue Eyes Intelligence Engineering 
Theorem 5.5 Every $\delta g^{*} \mathrm{~s}-\mathrm{T}^{*}{ }_{3 / 4}$-space is a $\mathrm{T}_{\alpha g^{\wedge}}-$ space.

Proof. Concede $\mathrm{N}$ be a $\delta \mathrm{g}^{*} \mathrm{~s}-\mathrm{T}^{*}{ }_{3 / 4}$-space, then each singleton is $\mathrm{g}^{*} \mathrm{~s}$-closed or $\delta$-open. As each singleton is $\mathrm{g}^{*} \mathrm{~s}$ -closed or $\alpha$-open, $\mathrm{N}$ is a $\mathrm{T}_{\alpha g^{\wedge}}$ - space

Note $5.6 \mathrm{~T}_{\alpha g \wedge}$ - space $\neq \delta g^{*} \mathrm{~S}-\mathrm{T}^{*}{ }_{3 / \mathbf{4}}$-space

Illustration 5.7 Consider $\mathrm{N}=\{\chi, \pi, \xi\}$ and $\tau=\{\mathrm{N}, \varphi$,

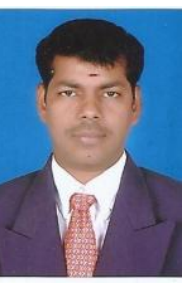
$\{\chi\},\{\xi\},\{\chi, \xi\},\{\pi, \xi\}\} . \mathrm{N}$ is a $\mathrm{T}_{a g^{\wedge}}$-space but $\neq \delta \mathrm{g}^{*} \mathrm{~s}-\mathrm{T}^{*}{ }_{3 / 4}-$ space.

Remark $5.8 \delta{ }^{*} \mathrm{~s}-\mathrm{T}^{*}{ }_{3 / 4}$-space and $\mathrm{T}_{1 / 2}$-space are self-reliant to one another

Illustration 5.9 Take $\mathrm{N}=\{\chi, \psi, \zeta\}$ and $\tau=\{\mathrm{N}, \varphi,\{\chi\}\}$. $(\mathrm{N}, \tau)$ is $\delta \mathrm{g}^{*} \mathrm{~s}-\mathrm{T}^{*}{ }_{3 / 4}$-space and $\neq \mathrm{T}_{1 / 2}$-space.

Illustration 5.10 Assume $\mathrm{N}=\{\lambda, \varsigma, \vartheta\}$ and $\tau=\{$ $\mathrm{N}, \varphi,\{\lambda\},\{\vartheta\},\{\lambda, \vartheta\},\{\varsigma, \vartheta\}\} . \mathrm{N}$ is $\mathrm{aT}_{1 / 2}$-space and $\neq$ $\delta \mathrm{g}^{*} \mathrm{~s}-\mathrm{T}^{*}{ }_{3 / 4}$-space

\section{ACKNOWLEDGMENT}

The biographer desire to give thanks to the conciliators for their impressive commentary and verdict which will guide to develop this publication

\section{REFERENCES}

1. S.P. Arya, T. Nour, Characterization of S-normal spaces. Indian J. Pure Appl.Math.21(8)(1990)717-719.

2. P.Bhattacharya and B.K. Lahiri, Semi generalized closed sets in Topology, Indian J.Math.,29(1987),375-382.

3. J. Dontchev and M. Ganster, On $\delta$-generalized closed sets and $T_{3 / 4}$ spaces, Mem. Fac. Sci. Kochi Univ.Ser.A, Math., 17(1996), 15-31.0

4. N.Levine, Semi-open sets and Semi-continuity in topological spaces Amer Math. Monthly, 70(1963), 36-41.

5. N.Levine, Generalized closed sets in topology Rend. Circ. Mat. Palermo, 19(1970)89-96.

6. H.Maki, R. Devi and K. Balachandran, Generalized $\alpha$-closed sets in topology,Bull. Fukuoka Univ. Ed part III, 42(1993), 13-21.

7. H. Maki, R. Devi and K. Balachandran, Associated topologies of generalized $\alpha$-closed sets and $\alpha$-generalized closed sets,Mem. Fac. Sci. Kochi Univ. Ser. A. Math.,15(1994), 57-63.

8. A.S.Mashhour,M.E Abd El-Monsef and S.N.El-Debb, On precontinuous and weak precontinuous mappings,Proc.Math, and Phys.Soc.Egyp 55(1982),47-53.

9. M.E Abd El-Monsef, S.Rose Mary and M. Lellis Thivagar, On $\alpha G$-closed sets in topological spaces, Assiut University Journal of Mathematics and Computr science, Vol 36(1), P-P.43-51(2007).

10. O. Njastad, On some classes of nearly open sets, Pacific J. Math., 15(1965), 961-970

11. M. Stone, Application of theory of Boolean rings to general topology,Trans .Amer. Math.Soc., 41(1937), 374-481.

12. M. K. R. S. Veerakumar, $g^{\wedge}$-closed sets in topological spaces, Bull. Allah. Math. Soc, 18(2003), 99-112.

13. N.V.Velico, H-closed topological spaces, Amer. Math. Soc. Transl. 78(1968), 103-118.

14. M. K. R. S. Veerakumar, $g^{*}$-semi closed sets, Acta Ciencia Indica. Acta Ciencia

15. Indica, Vol-29 M, No.1, 081(2003), 81-90

\section{AUTHORS PROFILE}

Dr. S. Rajakumar is currently a Assistant Professor in the Department of Mathematics in Kalasalingam Academy of Research And Education (Deemed to be University), Krishnankoil-626126. He obtained his Ph.D., degree in Manonmaniam Sundaranar University, TIrunelveli. His area of research interest is Topology and Bitopological spaces. He has $17+$ years of teaching experience. He has a few publications in standard journals. 